\title{
The Potential Role of Intravenous Magnesium Sulfate Administration on the Outcome of Acute Organophosphorus Toxicity. A prospective study in Poison Control Center Ain Shams University
}

\author{
Enas El Taftazany, Rabab Nabil Hafez and Ghada Mohamed Ebeid ${ }^{1}$
}

${ }^{1}$ Department of Forensic Medicine and Clinical Toxicology, Faculty of Medicine, Ain Shams University, Cairo, Egypt.

\begin{abstract}
Background: Organophosphate compounds (OP) have been used as pesticides and chemical warfare nerve agents worldwide. They are readily available because of inadequate regulations controlling their sale. The easy availability of these compounds has resulted in a gradual increase in accidental and suicidal poisoning. It also has resulted in many deaths that occur within hours of the ingestion. The efficacy of the traditional treatment of OP which includes atropine and oximes still an issue of debate.

Aim of the Work: Assessing the potential role of intravenous $\mathrm{MgSO}_{4}$ administration on the outcome of acutely OP intoxicated patients via a prospective single-blind randomized controlled trial in the Poison Control Center of Ain Shams University Hospitals (PCC-ASUH).

Patients and Methods: The study assesses the potential role of intravenous $\mathrm{MgSO}_{4}$ administration on the outcome of 40 acutely OP intoxicated patients within the period from 8-11-2016 to 18-1-2018. The study is prospective single-blinded randomized controlled trial that was carried out on patients admitted to (PCC-ASUH) with acute OP toxicity. Patients were divided according severity into moderate and severe groups then each group was subdivided into two subgroups; one received $\mathrm{MgSO}_{4}$ and the other didn't receive it. $\mathrm{MgSO}_{4}$ treated patients received $4 \mathrm{~g} / \mathrm{d}$ for only the first 24 hours after admission. Patients were observed for outcomes such as; mortality, total duration of hospital stay, need for ICU admission and its duration and intermediate syndrome and CVS toxicity occurrence.

Results: There was no significant difference in duration of ICU stay, total duration of hospital stay and need for mechanical ventilation between $\mathrm{MgSO}_{4}$ treated and non-treated patients.

$\mathrm{MgSO}_{4}$ administration may have decreased mortality, intermediate syndrome and CVS toxicity, but the difference was statistically insignificant between $\mathrm{MgSO}_{4}$ treated and non-treated patients

Conclusion: Our study found that intravenous $\mathrm{MgSO}_{4}$ administration didn't modify the total dose of atropine and oximes given to OP intoxicated patients during their hospital stay, also $\mathrm{MgSO}_{4}$ didn't modify the need for mechanical ventilation. Although $\mathrm{MgSO}_{4}$ had reduced the number of patients who developed intermediate syndrome and CVS toxicity, duration of ICU stay, total duration of hospital stay and mortality, but unfortunately this reduction was statistically insignificant.
\end{abstract}

\begin{tabular}{l|l} 
Keywords & Intravenous Magnesium Sulfate, Acute Organophosphorus Toxicity.
\end{tabular}

\section{Introduction}

$\mathrm{O}$ rganophosphorus (OP) compounds are largely used as pesticides worldwide. The easy availability of these compounds and lack of knowledge about the serious consequences resulting in increase in accidental and suicidal poisoning. According to the World Health Organization (WHO) three million cases of pesticide poisoning (mainly OP compounds) occur every year, resulting in an excess of 250,000 deaths, OP was also responsible for $40 \%$ of deaths among cases admitted to Poison Control Center
Ain Shams University (PCCASU) through year 2013 (Tawfik and ElHelaly, 2015).

OP insecticides are irreversible inhibitors of acetyl cholinesterase (AchE) enzyme. The clinical manifestations are due to excess acetylcholine (Ach) at muscarinic and nicotinic receptors with initial stimulation and then exhaustion of cholinergic synapses. There are three phases in acute OP poisoning: Acute cholinergic crises (first 48 hours), intermediate syndrome (IMS) (24-96 hours after 
poisoning) and OP induced delayed polyneuropathy (OPIDN) (Abdollahi and Karami-Mohajeri, 2012).

Atropine and oximes are traditionally used in the management of OP toxicity, but their efficacy is an issue of debate, some findings in animals suggest lack of efficacy of oximes in OP toxicity, other findings indicate no advantage of using oximes with atropine compared with atropine alone, so other agents that could improve the outcome should be studied (Pajoumand et al, 2004).

Magnesium sulfate $\left(\mathrm{MgSO}_{4}\right)$ was found to decrease Ach release in the central nervous system and at peripheral sympathetic and parasympathetic synapses by blocking calcium channels and also reduces CNS overstimulation. Also hypomagnesaemia caused by OP due to vomiting and diarrhea may be a contributory factor in severity and outcome, so intravenous MgSo4 administration is suggested by some authors to reduce hospitalization, morbidity and mortality of OP toxicity and its safety has been evaluated via some studies that concluded that intermittent injection of $\mathrm{MgSO}_{4}$ is safe (up to 16 gram) (Basher et al., 2013; Andrews et al., 2014).

Magnesium sulfate is inexpensive comparing to oximes which is expensive and ineffective after aging of acetyl cholinesterase and it is also familiar to doctors as it is widely used in different diseases like pre-eclampsia and bronchial asthma (Basher et al., 2013).

\section{Aim of the work}

The present study aims at:

Assessing the potential role of intravenous $\mathrm{MgSO}_{4}$ administration on the outcome of acutely OP intoxicated patients via a prospective single-blind randomized controlled trial in the Poison Control Center of Ain Shams University Hospitals (PCCASUH).

\section{Methodology}

The study assesses the potential role of intravenous $\mathrm{MgSO}_{4}$ administration on the outcome of acutely OP intoxicated patients within the period from 8-11-2016 to $18-1-2018$. The study is prospective single-blinded randomized controlled trial that was carried out on patients admitted to (PCC-ASUH) with acute OP toxicity.

\section{Patients}

Patients with acute OP toxicity of both sexes were included in the study; diagnosis was by history of exposure to OP compound, clinical manifestations and by measuring pseudocholinesterase enzyme level (Siva Prabodh et al., 2012).

The following patients were excluded from the study;

- Patients with co-ingestion of other drugs with OP

- Patients suffering from severe chronic systemic illness including liver failure, congestive heart failure, chronic respiratory disease and end stage renal disease (Basher et al., 2013 and Vijayakumar et al., 2017).

- Patients with any conditions that reduce pseudocholinestrease level like: parenchymal liver disease, malnutrition, inflammatory bowel disease, pregnant women with HELLP syndrome, myocardial infarction, AIDS (Lampón et al., 2012; Santarpia et al., 2013).

- Patients on medications that affect QT interval as Antipsychotics, tricyclic antidepressants and Class IA, IC antidysrrhythmics (Yap and Camm, 2003).

- Patients who were presented to emergency department 24 hours after exposure to OP.

\section{Sample size}

The study included 40 patients with acute organophosphorus intoxication, sample size was calculated using stata program, setting the type- 1 error $(\alpha)$ at 0.05 and the power $(1-\beta)$ at 0.8 .Results from a previous study (Benefits of magnesium sulfate in the management of acute human poisoning by organophosphorus insecticides) which was made by Pajoumand et al. (2004) were used to measure the sample size. The study showed that mean duration of hospitalization among treated group (Magnesium Sulfate group) was $2.97 \pm 2.18$ days while in group B (non-treated group) it was $5 \pm 1.9$ days. Calculation according to these values produced a minimal sample size of 20 cases per each group.

\section{Reference for program}

StataCorp. 2001. Statistical Software: Release 7.0. Ethical consideration:

College Station, TX: Stata Corporation.

An informed consent has been obtained from each patient or from his/her caregiver before inclusion in the study for obtaining medical history, clinical examination, electro-cardiogram (ECG), taking blood samples for laboratory investigations and for permission to give $\mathrm{MgSO}_{4}$, approval of PCC-ASUH director and ethical committee also was obtained.

Patients were classified according to the severity of intoxication as guided by Palaniappen, 2013 into:

- Group I: Moderate toxicity characterized by: Miosis, bradycardia, tachycardia, hypotension, hypertension, muscle twitching, fasciculation, bronchorrhea, bronchospasm.

\section{- Group II: Severe toxicity characterized by:}

Convulsions, respiratory failure, pulmonary edema, flaccid paralysis, involuntary micturition/defecation, cyanosis, deep coma by using a simple randomization method, every other patient was chosen to receive $\mathrm{MgSO}_{4}$ treatment, so group I was subdivided into;

- Group Ia: received the traditional treatment (decontamination, atropine and oximes) according to patient's needs plus placebo (saline)

- Group Ib: received the traditional treatment plus intravenous $\mathrm{MgSO}_{4}$

Group II was also subdivided into;

- Group IIa: received the traditional treatment (decontamination, atropine and oximes) according to patient's needs plus placebo (saline)

- Group IIb: received the traditional treatment plus intravenous $\mathrm{MgSO}_{4}$

- Patients who received intravenous $\mathrm{MgSO}_{4}$ were given $4 \mathrm{~g} / \mathrm{d}$ for only the first 24 hours after admission with monitoring its level as 
recommended by Pajoumand et al; 2004 and

Andrews et al., 2014.

\section{Laboratory data}

Two samples, 1 milliliter arterial blood for blood gas analysis and three milliliters venous blood for biochemical and toxicological analysis, were collected from each patient.

\section{Blood samples will be collected}

- On admission after initial stabilization

- Second sample after 24hours for determination of serum magnesium level

The following investigations were done as a part of routine management of acutely intoxicated patients:

Arterial blood gases analysis, serum electrolytes (Na, K, Mg), blood urea, serum creatinine, blood glucose level, plasma cholinesterase (pseudocholinesterase) and electrocardiogram (ECG).

Treatment and hospital admission: Recording the treatment measures received during hospital stay including decontamination methods, atropine, oximes and any other symptomatic treatment needed according to the patient condition according to the protocol of management in PCCASUH.

Outcome: All the patients were observed for short-term outcomes; that were either complete recovery or death and total duration of hospital stay.

Complications: All patients observed for the complications developed during hospital stay e.g intermediate syndrome, need for ICU admission, duration of ICU stay, need for mechanical ventilation, CVS toxicity.

Statistical analysis: The obtained data were revised, coded and organized for statistical analysis using SPSS (Statistical package for Social Science) version (18) software (SPSS Inc, USA). Data were presented and suitable analysis was done according to the type of data obtained for each parameter.

\section{Results}

Table (1): t-test analysis of amount of atropine and oximes given to groups a (MgSO4 treated) and b (MgSO4 non-treated):

\begin{tabular}{|c|c|c|c|c|c|c|c|c|c|}
\hline & & \multicolumn{6}{|c|}{$\mathrm{MgSO}_{4}$} & \multicolumn{2}{|c|}{ t-test } \\
\hline & & & es (1) & & & $\mathbf{0}($ & & $\mathbf{t}$ & P-value \\
\hline \multirow[t]{2}{*}{ Amount of atropine } & Range & 11 & - & 100 & 10 & - & 100 & \multirow[t]{2}{*}{2.128} & \multirow[t]{2}{*}{$0.040^{*}$} \\
\hline & Mean \pm SD & 74.600 & \pm & 33.049 & 51.150 & \pm & 36.553 & & \\
\hline \multirow[t]{2}{*}{ Amount of oxime } & Range & 1 & - & 20 & 1 & - & 12 & \multirow[t]{2}{*}{0.906} & \multirow[t]{2}{*}{0.374} \\
\hline & Mean \pm SD & 8.000 & \pm & 6.398 & 5.900 & \pm & 4.458 & & \\
\hline
\end{tabular}

-SD: standard deviation, $P>0.05$ : non-significant, $P<0.05$ : significant, $P<0.01$ : highly significant

Table (2): Chi-Square analysis of deaths among groups Ia, Ib, IIa and IIb:

\begin{tabular}{|c|c|c|c|c|c|c|c|c|c|}
\hline \multirow[t]{3}{*}{ Classification } & \multirow[t]{3}{*}{ Death } & \multicolumn{6}{|c|}{$\mathrm{MgSO}_{4}$} & \multirow{2}{*}{\multicolumn{2}{|c|}{ Chi-Square }} \\
\hline & & \multicolumn{2}{|c|}{ Yes (b) } & \multicolumn{2}{|c|}{ No (a) } & \multicolumn{2}{|c|}{ Total } & & \\
\hline & & $\mathbf{N}$ & $\%$ & $\mathbf{N}$ & $\%$ & $\mathbf{N}$ & $\%$ & $\mathrm{X} 2$ & P-value \\
\hline \multirow[t]{2}{*}{ Moderate (I) } & Yes & 0 & 0.00 & 1 & 8.33 & 1 & 4.17 & \multirow[t]{2}{*}{1.043} & \multirow[t]{2}{*}{0.307} \\
\hline & No & 12 & 100.00 & 11 & 91.67 & 23 & 95.83 & & \\
\hline \multirow[t]{2}{*}{ Severe (II) } & Yes & 2 & 25.00 & 5 & 62.50 & 7 & 43.75 & \multirow[t]{2}{*}{2.286} & \multirow[t]{2}{*}{0.131} \\
\hline & No & 6 & 75.00 & 3 & 37.50 & 9 & 56.25 & & \\
\hline
\end{tabular}

$X 2$ Chi-square statistical analysis test, $N$ : number , $P>0.05$ : non significant, $P<0.05$ : significant, $P<0.01$ : highly significant, $N$ : number

Table (3): t-test statistical analysis of total duration of hospital stay of groups Ia, Ib, IIa and IIb:

\begin{tabular}{|c|c|c|c|c|c|c|c|c|c|c|}
\hline \multirow[t]{2}{*}{ Classification } & & & \multicolumn{6}{|c|}{$\mathrm{MgSO}_{4}$} & \multicolumn{2}{|c|}{ t-test } \\
\hline & & & \multicolumn{3}{|c|}{ Yes (b) } & \multicolumn{3}{|c|}{ No (a) } & $\mathbf{t}$ & P-value \\
\hline \multirow[t]{2}{*}{ Moderate (I) } & \multirow{2}{*}{$\begin{array}{c}\text { Total duration } \\
\text { of hospital stay (day) }\end{array}$} & Range & 0.5 & - & 7 & 1 & - & 5.5 & \multirow[t]{2}{*}{0.331} & \multirow[t]{2}{*}{0.745} \\
\hline & & Mean \pm SD & 2.350 & \pm & 1.973 & 2.063 & \pm & 1.635 & & \\
\hline \multirow[t]{2}{*}{ Severe (II) } & \multirow{2}{*}{$\begin{array}{c}\text { Total duration } \\
\text { of hospital stay (day) }\end{array}$} & Range & 1 & - & 6 & 0.5 & - & 9 & \multirow[t]{2}{*}{-0.098} & \multirow[t]{2}{*}{0.924} \\
\hline & & Mean \pm SD & 3.313 & \pm & 1.981 & 3.438 & \pm & 3.029 & & \\
\hline
\end{tabular}

-SD: standard deviation, $P>0.05$ : non-significant, $P<0.05$ : significant, $P<0.01$ : highly significant 
Table (4):Chi-Square analysis of intermediate syndrome occurrence in groups Ia, Ib, IIa and IIb in the present study:

\begin{tabular}{|c|c|c|c|c|c|c|c|c|c|}
\hline \multirow[t]{3}{*}{ Classification } & \multirow{3}{*}{$\begin{array}{c}\text { Int. } \\
\text { Syndrome }\end{array}$} & \multicolumn{6}{|c|}{$\mathrm{MgSO}_{4}$} & \multirow{2}{*}{\multicolumn{2}{|c|}{ Chi-Square }} \\
\hline & & \multicolumn{2}{|c|}{ Yes (b) } & \multicolumn{2}{|c|}{ No (a) } & \multicolumn{2}{|c|}{ Total } & & \\
\hline & & $\mathbf{N}$ & $\%$ & $\mathbf{N}$ & $\%$ & $\mathbf{N}$ & $\%$ & $\mathrm{X} 2$ & P-value \\
\hline \multirow[t]{2}{*}{ Moderate (I) } & Yes & 0 & 0.00 & 1 & 8.33 & 1 & 4.17 & \multirow[t]{2}{*}{1.043} & \multirow[t]{2}{*}{0.307} \\
\hline & No & 12 & 100.00 & 11 & 91.67 & 23 & 95.83 & & \\
\hline \multirow[t]{2}{*}{ Severe (II) } & Yes & 4 & 50.00 & 5 & 62.50 & 9 & 56.25 & \multirow[t]{2}{*}{0.254} & \multirow[t]{2}{*}{0.614} \\
\hline & No & 4 & 50.00 & 3 & 37.50 & 7 & 43.75 & & \\
\hline
\end{tabular}

$X 2$ Chi-square statistical analysis test, $N$ : number , $P>0.05$ : non significant, $P<0.05$ : significant, $P<0.01$ : highly significant, $N$ : number

Table (5): t-test analysis of duration of ICU stay of groups Ia, Ib, IIa and IIb in the present study:

\begin{tabular}{|c|c|c|c|c|c|c|c|c|c|c|}
\hline \multirow[t]{2}{*}{ Classification } & & & \multicolumn{6}{|c|}{$\mathrm{MgSO}_{4}$} & \multicolumn{2}{|c|}{ t-test } \\
\hline & & & \multicolumn{3}{|c|}{ Yes (b) } & \multicolumn{3}{|c|}{ No (a) } & $\mathbf{t}$ & P-value \\
\hline Moderate (I) & \multirow{2}{*}{$\begin{array}{c}\text { Duration of } \\
\text { ICU stay (day) }\end{array}$} & Range & 1 & - & 8 & 1 & - & 9 & \multirow[t]{2}{*}{0.913} & \multirow[t]{2}{*}{0.371} \\
\hline & & Mean \pm SD & 3.125 & \pm & 2.278 & 2.250 & \pm & 2.417 & & \\
\hline \multirow[t]{2}{*}{ Severe (II) } & \multirow{2}{*}{$\begin{array}{c}\text { Duration of } \\
\text { ICU stay (day) }\end{array}$} & Range & 1 & - & 7 & 2 & - & 10 & \multirow[t]{2}{*}{-0.293} & \multirow[t]{2}{*}{0.774} \\
\hline & & Mean \pm SD & 4.000 & \pm & 2.204 & 4.375 & \pm & 2.875 & & \\
\hline
\end{tabular}

-SD: standard deviation, $P>0.05$ : non-significant, $P<0.05$ : significant, $P<0.01$ : highly significant

Table (6): Chi-Square analysis of need for mechanical ventilation and CVS toxicity in groups a and $b$ in the present study:

\begin{tabular}{|c|c|c|c|c|c|c|c|c|c|}
\hline & \multicolumn{6}{|c|}{$\mathrm{MgSO}_{4}$} & \multirow{2}{*}{\multicolumn{2}{|c|}{ Chi-Square }} \\
\hline & & \multicolumn{2}{|c|}{ Yes (b) } & \multicolumn{2}{|c|}{ No (a) } & \multicolumn{2}{|c|}{ Total } & & \\
\hline & & $\mathbf{N}$ & $\%$ & $\mathbf{N}$ & $\%$ & $\mathbf{N}$ & $\%$ & $\mathrm{X} 2$ & P-value \\
\hline \multirow[t]{2}{*}{ Need for mech. Vent. } & Yes & 7 & 35.00 & 7 & 35.00 & 14 & 35.00 & \multirow[t]{2}{*}{0.000} & \multirow[t]{2}{*}{1.000} \\
\hline & No & 13 & 65.00 & 13 & 65.00 & 26 & 65.00 & & \\
\hline \multirow{4}{*}{$\begin{array}{l}\text { CVS toxicity } \\
\text { And ECG abnormalities }\end{array}$} & No & 19 & 95.00 & 17 & 85.00 & 36 & 90.00 & \multirow[t]{4}{*}{2.111} & \multirow[t]{4}{*}{0.550} \\
\hline & Prolonged QT & 1 & 5.00 & 1 & 5.00 & 2 & 5.00 & & \\
\hline & Ventricular arrhythmia & 0 & 0.00 & 1 & 5.00 & 1 & 2.50 & & \\
\hline & Inverted $\mathrm{T}$ wave & 0 & 0.00 & 1 & 5.00 & 1 & 2.50 & & \\
\hline
\end{tabular}

$X 2$ Chi-square statistical analysis test, $N$ : number , $P>0.05$ : non-significant, $P<0.05$ : significant, $P<0.01$ : highly significant, $N$ : number

Table (7): Odds ratio and 95.0\% confidence interval of death, intermediate syndrome, ICU admission, need for mechanical ventilation and CVS toxicity in patients under the study:

\begin{tabular}{|c|c|c|c|c|}
\hline & Odd's ratio & \multicolumn{2}{|l|}{$\mathbf{9 5 . 0 \%}$ C.I. for Odd's ratio } & P-value \\
\hline Death & 0.137 & 0.013 & 1.417 & 0.095 \\
\hline Int. Syndrome & 0.140 & 0.006 & 3.146 & 0.215 \\
\hline ICU admission & 3.395 & 0.481 & 23.976 & 0.220 \\
\hline Need for mech. Vent. & 6.122 & 0.283 & 132.457 & 0.248 \\
\hline CVS toxicity & 0.498 & 0.116 & 2.136 & 0.348 \\
\hline
\end{tabular}

$P>0.05$ : non-significant, $P<0.05$ : significant, $P<0.01$ : highly significant

\section{Discussion}

Organophosphates are one of the most common causes of poisoning, especially in developing countries, and despite the great developments in the intensive care management, ingestion of OP compounds is still a greatly contributing agent of poisoning with mortality rates reaching up to $10-20 \%$. So early diagnosis and appropriate treatment is often lifesaving (Chowdhary et al., 2014).

Classic management of OP toxicity includes giving atropine to reverse the muscarinic effects and giving oximes to break up the OP/AChE complex to restore cholinesterase activity and neutralize muscarinic and nicotinic manifestations (Indu et al., 2016).

Oximes should be given as soon as possible before complex aging takes place, it is reported that there is a beneficial response as long as 24 hours after exposure. Unfortunately, these agents do not favorably affect the outcome, based on several parameters including total atropine requirement and duration of hospitalization (Sungur and Guven, 2001).

The efficacy of the traditional antidotes of organophosphorus remains a major issue of debate, thus alternative or adjunctive treatments need to be 
explored and one of the proposed agents is $\mathrm{MgSO}_{4}$ (Syed et al., 2015).

The present study was prospective singleblinded randomized controlled trial that was carried out on patients admitted to (PCC-ASUH) with acute OP toxicity who were selected according to predetermined criteria. This work aimed to assess the potential role of intravenous $\mathrm{MgSO}_{4}$ administration on the outcome of patients with acute OP intoxication which included mortality, total duration of hospital stay, need for ICU admission and its duration, morbidities during hospitalization including development of intermediate syndrome, need for mechanical ventilation and CVS toxicity. Patients in our study were classified as regard the severity of intoxication into moderate and severe groups guided by Palaniappen, (2013), and each group was subdivided into two subgroups; one received $\mathrm{MgSO}_{4}(50 \%)$ and another subgroup that didn't receive $\mathrm{MgSO}_{4}(50 \%)$.

In the current study, there was no significant difference in total dose of atropine and oximes between $\mathrm{MgSO}_{4}$-treated and non-treated patients, this was in agreement with Pajoumand et al., 2004.

Since there are numerous variations in the optimal dosing regimen of atropine (Abedin et al., 2012) and the lack of dose-response studies that aim to identify its ideal dosage regimen (Eddleston and Chowdhury, 2016) so it is difficult to compare between results of different poison control centers as regards the effect of intravenous $\mathrm{MgSO}_{4}$ administration on modifying the dose of atropine in OP poisoning.

In the present study, number of patients who developed intermediate syndrome was more in MgSo4 non-treated patients, but the difference was insignificant. There was no difference in need for mechanical ventilation between $\mathrm{MgSo} 4$ treated and non-treated patients, this was in contrast with a study done by Vijayakumar et al., 2017 who found that MgSo4 had reduced the need for mechanical ventilation.

Cardiac manifestations are commonly observed in patients with OP toxicity. There are three stages of cardiac toxicity, first short period of sympathetic overstimulation followed by prolonged period of parasympathetic activity then QT prolongation followed by torsade de pointes ventricular tachycardia and then ventricular fibrillation (Balouch et al., 2012).

In the present study, number of patients who developed CVS toxicity was more in MgSo4 nontreated patients than MgSo4 treated patients, but the difference was insignificant. Studies that discuss the effect of intravenous magnesium in prevention of CVS toxicity are insufficient.

In contrast to Vijayakumar et al. (2017) who found that $\mathrm{MgSO}_{4}$ had significantly reduced ICU stay duration, our study found that duration of ICU stay wasn't modified by intravenous $\mathrm{MgSO}_{4}$ administration. As regard total duration of hospital stay, our study found that there was no significant difference in total duration of hospital stay between $\mathrm{MgSO}_{4}$ treated and non-treated patients. this was in contrast with Pajoumand et al. (2004).
Our study found that there was no significant difference in mortality between $\mathrm{MgSO}_{4}$ treated and non-treated patients. This agreed with results of a study done by Gunay et al. (2010) and Vijayakumar et al. (2017) but it was in contrast with Pajoumand et al. (2004) who had found that MgSo4 reduced the mortality significantly.

\section{Conclusion}

In conclusion, the present study found that intravenous $\mathrm{MgSO}_{4}$ administration didn't modify the total dose of atropine and oximes given to OP intoxicated patients during their hospital stay, also $\mathrm{MgSO}_{4}$ didn't modify the need for mechanical ventilation. Although $\mathrm{MgSO}_{4}$ had reduced the number of patients who developed intermediate syndrome and CVS toxicity, duration of ICU stay, total duration of hospital stay and mortality, but unfortunately this reduction was statistically insignificant.

In fact, the studies suggesting beneficial effects from new treatments such as $\mathrm{MgSO}_{4}$ are very small; they are carried out on a local basis, no multicentric studies are available, and finally, results are conflicting. Further studies related to the improvement of the management of poisoning with OP compounds are required.

\section{References}

Abdollahi M and Mohajeri S (2012): A comprehensive review on experimental and clinical findings in intermediate syndrome caused by organophosphate poisoning, Toxicology and Applied Pharmacology 258, P: 309-314

Abedin M, Sayeed A, Basher A, Maude R, et al., (2012): Open-Label Randomized Clinical Trial of Atropine Bolus Injection Versus Incremental Boluses Plus Infusion for Organophosphate Poisoning in Bangladesh, Journal of Medical Toxicology; 8: 108-117.

Andrews MA, Madhavan I, Parakadavathu RT , et al., (2014): Outcome of Patients with Cholinergic Insecticide Poisoning Treated with Gastric Lavage: A Prospective Observational Cohort Study.Asia Pacific Journal of Medical Toxicology; 3(4) (146-151).

Balouch Gh., Yousfani A., Jaffery M., et al., (2012): Electrocardiographical manifestations of acute organophosphate poisoning, World Applied Sciences Journal 16 (8), P: 1118-1122

Basher A, Rahman SH, Ghose A, et al., (2013): Phase II study of magnesium sulfate in acute organophosphate pesticide poisoning. Clinical Toxicology, 51(1) (35-40).

Chowdhary SH, Bhattacharyya R and Banerjee D (2014): Acute organophosphorus poisoning, Clinica Chimica Acta; 431: 66-76.

Eddleston M. and Chowdhury F. R. (2016): Pharmacological treatment of organophosphorus insecticide poisoning: the old and the (possible) new. British journal of clinical pharmacology, 81(3), 462-470.

Gunay N, Kekec Z, Demiryurek S, et al., (2010): Cardiac effects of magnesium sulfate pretreatment on acute dichlorvos-induced organophosphate poisoning: an experimental 
study in rats. Biological Trace Element Research; 133(2), 227-235.

Indu TH, Raja D, Manjunatha B et al., (2016): Can Galantamine Act as an Antidote for Organophosphate Poisoning? A Review. Indian Journal of Pharmaceutical Sciences, 78(4), 428-435.

Lampón N, Hermida-Cadahia EF, Riveiro A, et al.,(2012). Association between butyrylcholinesterase activity and low-grade systemic inflammation. Ann Hepatol; 11:356363.

Pajoumand A, Shadnia S, Rezaie A, et al., (2004): Benefits of magnesium sulfate in the management of acute human poisoning by organophosphorus insecticides; Human \& Experimental Toxicology; 23; 565 -569.

Palaniappen V (2013): Current Concepts in the Management of Organophosphorus Compound Poisoning: Medicine Update. Mumbai, India: The Association of Physicians of India; (427) (33).

Santarpia L, Grandone I, Contaldo F , et al., (2013): Butyrylcholinesterase as a prognostic marker: a review of the literature. Journal of cachexia, sarcopenia and muscle, 4(1), 31-39.

Siva Prabodh V, Padma Vijaya Sree A, Sarma DVHS, et al., (2012): Activity of Serum Cholinesterase in Organophosphorus poisoning cases: A prospective study. Journal of pharmaceutical and biomedical sciences ; 20) (03)

StataCorp. 2001. Statistical Software: Release 7.0. College Station, TX: Stata Corporation.

Sungur M and Guven M (2001): Intensive care management of organophosphate Insecticide poisoning. Crit Care; 5(4): 211-15.

Syed S, Gurcoo SA, Farooqui AK, et al., (2015): Is the World Health Organization-recommended dose of pralidoxime effective in the treatment of organophosphorus poisoning? A randomized, double-blinded and placebocontrolled trial. Saudi journal of anaesthesia, 9(1), 49.

Tawfik H and ElHelaly H (2015): Toxiclogical Profile of Acutely Poisoned Cases Admitted to Poison Control Cente, Ain Shams University Hospitals during Year 2013.Ain Shams Journal of Forensic Medicine and Clinical Toxicology; (24) (154-163)

Vijayakumar HN, Sudheesh Kannan CT, Duggappa DR, et al., (2017): Study of effect of magnesium sulphate in management of acute organophosphorous pesticide poisoning. Anesthesia, essays and researches, 11(1), 192.

Yap YG and Camm AJ (2003). Drug induced QT prolongation and torsades de pointes. Heart, 89(11), 1363-1372. 


\section{الملخص العربي}

\section{الدور الحتمل للحقن الوريدي لسلفات الماغنيسيوم في نتيجة التسمم الحاد بالمبيدات الفسفوريه العضوية ـ دراسة مستقبلية في مركز علاج التسمم بمستشفيات جامعه عين شمس سئس}

\section{ايناس التفتازائ و رباب نبيل حافظ و غادة محمد عبيد}

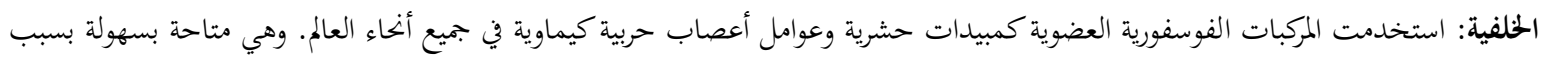

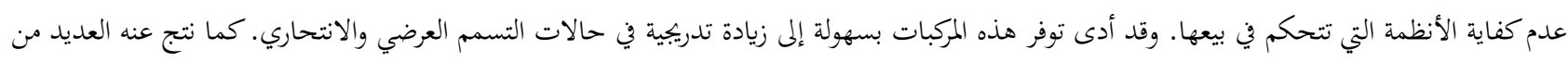

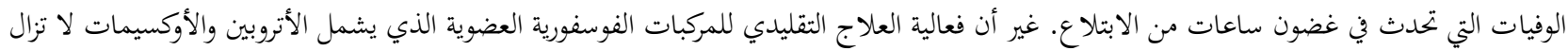
مسألة نقاش.

الهدف من الدراسة: تقييم الدورالمتمل للحقن الوريدي لسلفات الماغنسيوم على النتيجة المترتبة على التسمم الحاد بالمركبات الفسفورية العضوية عن

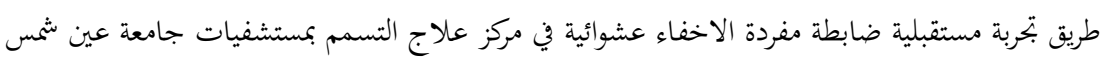
المرضى والأساليب: تقيم الدراسة الدور المتمل للحقن الوريدي لسلفات الماغنيسيوم على النتيجة المترتبة على التسمم الحاد بلمكركبات الفسفورية

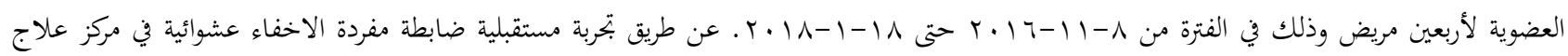

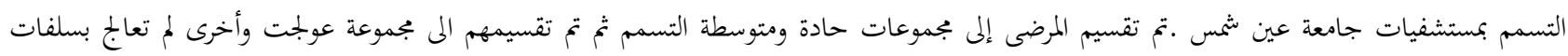

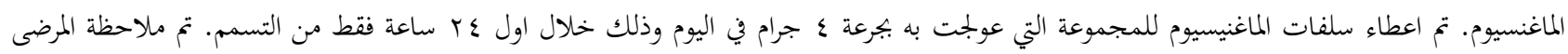

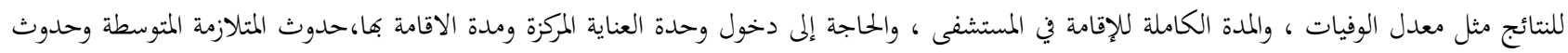
تسمم للقلب قالاوعية الدموية.

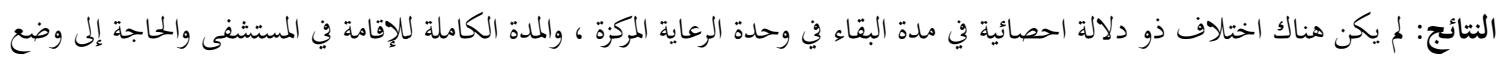

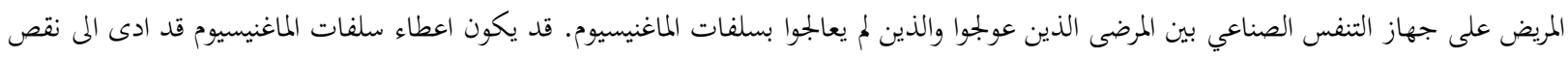

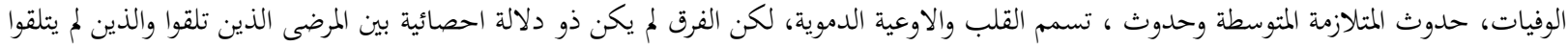
سلفات الماغنيسيوم الحلاصة: وجدت دراستنا أن الحقن الوريدي لسلفات الماغنيسيوم لم يقم بتعديل الجرعة الإجمالية من الأتروبين و الاوكسيمات الممنوحة

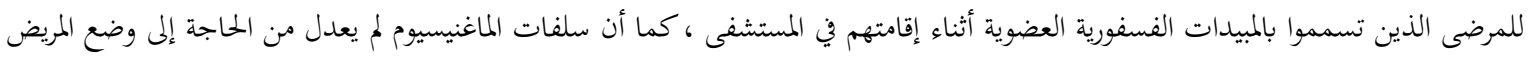

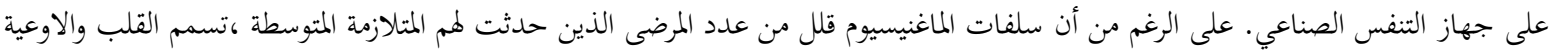

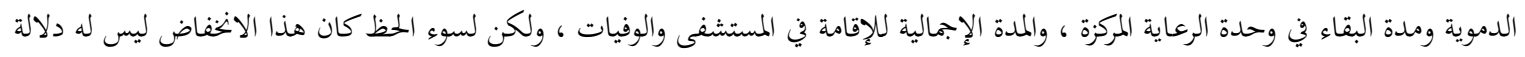

